\title{
Development of a rapid loop-mediated isothermal amplification assay for diagnosis and assessment of cure of Leishmania infection
}

Sandeep Verma', Ruchi Singh ${ }^{1}$, Vanila Sharma ${ }^{1}$, Ram Avtar Bumb², Narendra Singh Negi ${ }^{3}$, V Ramesh ${ }^{4}$ and Poonam Salotra ${ }^{1 *}$

\begin{abstract}
Background: Leishmaniasis is a spectrum of diseases with great relevance to public health. Conventional diagnostic methods are time consuming, needing trained personnel. A robust, rapid and cost effective diagnostic test is warranted for on-time diagnosis and field application.

Methods: We have developed a loop mediated isothermal amplification (LAMP) assay with primers $(n=6)$ based on Leishmania donovani kDNA for detection of Leishmania infection, using a closed tube to prevent cross-contamination. The assay was used to detect Leishmania infection in biological samples obtained from patients of visceral leishmaniasis (VL), post kala-azar dermal leishmaniasis (PKDL) and cutaneous leishmaniasis (CL).

Results: The assay was positive for L. donovani, L. tropica and L. major parasites, with the highest sensitivity towards L. donovani ( $1 \mathrm{fg}$ DNA). The high sensitivity of the assay for detection of L. donovani was reflected in its ability to detect parasite DNA within 30 min of amplification time with a threshold detection limit of $\geq 25$ copies per reaction. The assay detected parasite in 64 of $66 \mathrm{VL}$ blood samples (sensitivity, 96.9\%; 95\% Cl: 89.6-99.2\%), 15 of $15 \mathrm{VL}$ bone marrow aspirate samples (sensitivity, 100\%; 95\% Cl:79.6-100\%), 65 of 67 PKDL tissue biopsy samples (sensitivity, 97\%; 95\% Cl:89.7-99.2\%). The assay was evaluated in a few cases of CL wherein it was found positive in 8 of 10 tissue biopsies (sensitivity, 80\%; 95\% Cl: 49-94.3\%). The assay was negative in all control blood ( $n=76)$ and tissue biopsy $(n=24)$ samples (specificity, 100\%; 95\% Cl: 96.3-100\%). Further, the assay was evaluated for its utility in assessment of cure in treated VL and PKDL patients. The assay detected parasite DNA in 2 of 20VL blood samples and 2 of 21 PKDL tissue samples. Out of 4 cases that were positive for parasite DNA at post treatment stage, 2 patients (1VL and $1 \mathrm{PKDL}$ ) returned with relapse.
\end{abstract}

Conclusions: The study demonstrated a Leishmania genus specific closed tube LAMP assay for reliable and rapid molecular diagnosis of VL and PKDL with potential for application in assessment of cure.

Keywords: Leishmania, VL, PKDL, Diagnosis, LAMP

\footnotetext{
* Correspondence: salotra@vsnl.com

${ }^{1}$ National Institute of Pathology (ICMR), Safdarjung Hospital Campus, New

Delhi 110029, India

Full list of author information is available at the end of the article
} 


\section{Background}

Leishmaniasis, a group of diseases caused by protozoan parasite Leishmania is transmitted to humans by the bite of infected phlebotomine female sandflies. The disease is endemic in about 98 countries, affecting 12 million people worldwide. Clinical manifestations include cutaneous leishmaniasis (CL), mucocutaneous leishmaniasis (MCL) to the deadly visceral leishmaniasis (VL). VL mostly prevalent in tropical regions is caused by the parasites of L. donovani complex. In 2014, more than 90\% of new cases of VL reported to WHO occurred in six countries: Brazil, Ethiopia, India, Somalia, South Sudan and Sudan [1]. Post kala-azar dermal leishmaniasis (PKDL) is a neglected complication of VL, characterized by macular, maculopapular and nodular lesions in a patient who has recovered from VL. In India and Bangladesh, PKDL is reported in $5-15 \%$ of patients treated for VL, usually after an interval of a few months to several years $[2,3]$, however in Sudan $50-60 \%$ of VL cases develop PKDL within a few weeks of treatment [4]. The need to identify persons affected with PKDL and treat them as a part of VL control programs have been emphasized since PKDL patients are considered as an important reservoir for the parasite during inter-epidemic periods of VL [4]. In India, CL is primarily endemic in the western Thar region of Rajasthan, particularly in Bikaner, where L. tropica is the major causative agent [5].

Microscopic examination of tissue smears is considered as the gold standard for the definitive diagnosis of VL and PKDL that suffers from low sensitivity. The sensitivity of microscopy for VL ranges from 93-99\% for spleen aspirate to $53-86 \%$ for bone marrow, and 53-65\% for lymph node aspirates [6] while for PKDL diagnosis it is higher for nodular cases $(67-100 \%)$ compared to papular (36-69\%) or macular (7-33\%) cases [7]. Serological methods (rK39 strip test, enzyme-linked immunosorbent assay, direct agglutination test etc.) are highly sensitive, however, fail to distinguish between past and present infections hence are not conclusive for PKDL diagnosis [8-11]. In last several years advances in the polymerase chain reaction (PCR) based methods have been introduced for diagnosis of leishmaniasis [12-15]. Several PCR protocols have been developed for detection of Leishmania parasite, such as triplex PCR [16], multiplex PCR [17], restriction fragment length polymorphism (RFLP) analysis and nested PCR [18]. Quantitative Real-time PCR (Q-PCR) has emerged as a highly sensitive tool for VL and PKDL diagnosis with simultaneous quantification of the parasite burden [19-22]. However, these assays are not used for routine diagnosis of Leishmania infection as these require of well equipped laboratory facilities along with technical expertise.

Loop-mediated isothermal amplification (LAMP) assay, a method to amplify DNA with rapidity and high specificity under isothermal conditions, has emerged as an efficient tool in the field of diagnostics [23]. LAMP assay is rapid and cost effective as compared to PCR, offering improved sensitivity and a higher tolerance for inhibitors present in a number of clinical samples [24, 25]. Shorter reaction time with visual judgment of positivity without requiring sophisticated equipments makes it an attractive diagnostic method for field application.

Although, a few studies employing LAMP assay to diagnose Leishmania infection are known [26-32] however, these assays are limited in their utility because of the false positivity due to cross contamination [29], or prolonged reaction time [31] or the use specialized equipment [32]. Here, we have developed a LAMP assay based on kinetoplast minicircle DNA (kDNA) of L.donovani for reliable and rapid diagnosis of Leishmania infection in a closed tube manner using SYBR Green I for detection of the amplified product.

\section{Methods \\ Parasite DNA}

DNA from different Leishmania spp. including L. donovani AG83 (MHOM/IN/83/AG83), L. major ASKH (MHOM/ SU/73/5ASKH) and L. tropica WR 683 (MHOM/ SU/58/ OD) were used in the study. All parasite cultures were propagated in medium 199 supplemented with $25 \mathrm{mM}$ HEPES, pH 7.5 and $10 \%$ fetal calf serum. Parasites were harvested in the late log phase and washed in phosphatebuffered saline prior to DNA isolation using Promega genomic wizard DNA isolation kit (Promega Corporation, USA) according to the manufacturer's instructions.

\section{Clinical samples}

$\mathrm{VL}$ and PKDL patients originating from Bihar and reporting respectively to Departments of Medicine and Dermatology, Safdarjung Hospital, New Delhi, were included in this study. The patients with characteristic symptoms of VL (fever, hepatosplenomegaly, anemia and leucopenia) and PKDL (on clinico-histopathological observations) who were positive by rK39 strip test were included in this study. All the cases were confirmed by Q-PCR assay [21]. Peripheral blood ( $0.5 \mathrm{ml}$ from 66 cases) and bone marrow aspirate BMA (100 $\mu$ l from 15 cases) were collected from VL patients while tissue biopsy (4-6 mm punch biopsy from 67 cases) were collected from PKDL patients at pre-treatment stage. VL and PKDL samples used in this study included those reported earlier [29] in addition to new cases that reported thereafter. Tissue biopsy sample DNA of Q-PCR [5] confirmed CL $(n=10)$ cases who reported to Department of Skin, STD \&Leprosy, S.P. Medical College, Bikaner (Rajasthan), India, were also included in this study. Blood $(0.5 \mathrm{ml})$ samples from healthy volunteers (endemic $n=24$; non-endemic, $n=38$ ), malaria patients $(n=7)$ and tuberculosis patients $(n=7)$ as 
well as tissue biopsy (4-6 $\mathrm{mm}$ punch biopsy) samples from leprosy patients $(n=18)$ and cases of fungal diseases (Sporotrichosis or Pityriasis lichenoides chronica) $(n=6)$ were included as controls.

\section{DNA isolation from clinical samples}

Blood and bone marrow sample was collected in heparinized tubes. DNA extraction was performed using QIAamp DNA Blood mini kit (Qiagen, Germany) according to manufacturer's instructions. DNA was isolated from $200 \mu \mathrm{L}$ of blood and eluted in $50 \mu \mathrm{L}$ nuclease free water. In case of BMA sample, $100 \mu \mathrm{L}$ of BMA was used and eluted in $100 \mu \mathrm{L}$ nuclease free water. In order to achieve maximum yield in BMA samples, digestion was performed overnight with proteinase $\mathrm{K}$ in lysis solution [29]. Punch biopsy (4-6 $\mathrm{mm}$ ) sample was taken under sterile conditions from the dermal lesions of PKDL and CL cases in NET buffer $(150 \mathrm{mM} \mathrm{NaCl}, 15 \mathrm{mM}$ Tris- $\mathrm{HCl} \mathrm{pH} 8.30$ and $1 \mathrm{mM}$ EDTA). DNA was extracted and eluted in $100 \mu \mathrm{l}$ of nuclease free water using QIAamp DNA Tissue kit according to manufacturer's instructions.

\section{Design of LAMP primers}

Sets of outer forward primer (F3), outer backward primer (B3), forward inner primer (FIP) and backward inner primer (BIP) targeting regions of $L$. donovani $\mathrm{kDNA}$ sequence (GenBank accession no. Y11401.1) were designed using the online Primer Explorer V4 software (Eiken Chemical Co. Ltd., Japan, http://primerexplorer.jp/elamp4.0.0/index.html). Loop primers [Forward loop primer (FLP) and Backward loop primer (BLP)] were designed manually. Three primer sets were tested and the primer set giving highest sensitivity was used in the study. The primer set used is shown in Fig. 1.

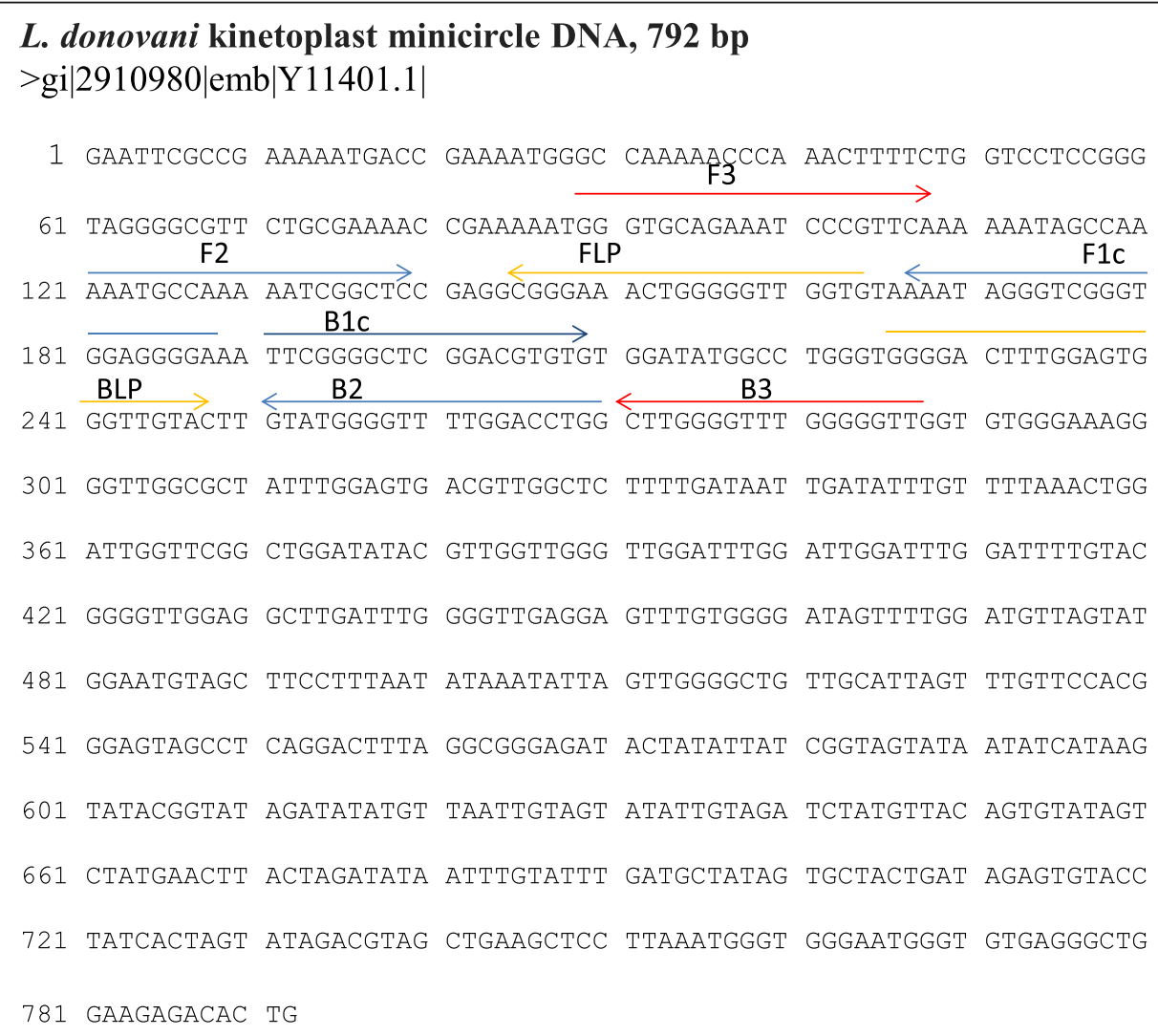

Primer sequences

F3- 5'GGTGCAGAAATCCCGTTCAA3', B3-5'CAACCCCCAAACCCCAAG3'

Forward Inner Primer (FIP=F1 c-F2)-5'CCCCTCCACCCGACCCTATTTAAATGCCAAAAATCGGCTCC3', Backward Inner Primer (BIP=B1c-B2)5'TCGGGGCTCGGACGTGTGT-CCAGGTCCAAAACCCCATAC3' Forward loop primer (FLP)- 5'CACCAACCCCCAGTTTCCCG3', Backward loop primer (BLP)- 5' GGGGACTTTGGAGTGGGTTGTA3'

Fig 1 Primers for LAMP assay. Primers for LAMP assay were designed for amplification of Leishmania DNA from L. donovani kinetoplast minicircle sequence (Acession no Y11401) using Primer Explorer V4 software. A total of six primers (F3, B3, FIP, BIP, FLP and BLP) were designed for the LAMP assay 


\section{Cloning and sequencing of LAMP amplicon from Leishmania spp}

The LAMP amplicon from kDNA minicircle from Leishmania spp, was amplified using F3 and B3 primers. The PCR reaction mixture of final volume $50 \mu \mathrm{l}$ contained 50 pmol of F3 and B3 primers, 10 ng of parasite DNA ( $L$. donovani, L. major and L. tropica), $200 \mu \mathrm{M}$ each of dNTP mix, 2 mM MgSO4, and 1 U Platinum Taq DNA polymerase (Invitrogen, USA) in $1 \times$ Taq buffer. PCR reaction conditions included initial denaturation at $94{ }^{\circ} \mathrm{C}$ for $2 \mathrm{~min}$., followed by 35 cycles of $94{ }^{\circ} \mathrm{C}$ for 15 s., $62{ }^{\circ} \mathrm{C}$ for $30 \mathrm{~s}$., $68{ }^{\circ} \mathrm{C}$ for $30 \mathrm{~s}$, and final extension at $68^{\circ} \mathrm{C}$ for $2 \mathrm{~min}$. The PCR amplicon (200 bp) along with $100 \mathrm{bp}$ DNA ladder were resolved by $2 \%$ agarose gel electrophoresis. PCR amplicons were purified and ligated into pGEMT easy cloning vector (Promega Corporation, USA) following manufacturer's instructions. Recombinant plasmids were characterized using restriction enzyme EcoRI (MBI Fermentas, USA) for insert fall out (200 bp). The amplicons were cloned into pGEMT vector and transformed into E.coli $\mathrm{DH} 5 \alpha$ strains. The positive clones were screened by blue and white selection on X-gal and IPTG containing Luria-Bertani agar plates. The white colonies were selected and sequenced using T7/SP6 primers on Automated Sequencer 3730 Version 3.0 (ABI PRISM).

\section{LAMP assay}

The LAMP reaction was performed in $25 \mu \mathrm{l}$ of reaction mixture containing $40 \mathrm{pmol}$ each of FIP and BIP primers, 5 pmol each of F3 and B3 primers,20 pmol each of the FLP and BLP, $1.4 \mathrm{mM}$ of each deoxynucleoside triphosphate, $0.8 \mathrm{M}$ betaine, $20 \mathrm{mM}$ Tris- $\mathrm{HCl}, \mathrm{pH} 8.8$, $10 \mathrm{mMKCl}, 10 \mathrm{mM}\left(\mathrm{NH}_{4}\right)_{2} \mathrm{SO}_{4}, 8 \mathrm{mM} \mathrm{MgSO}_{4}, 0.1 \%$ TritonX-100, 8 units of Bst DNA polymerase large Fragment (New England Biolabs, Ipswich, MA), and $2 \mu \mathrm{l}$ of DNA from parasites and clinical specimen. Before starting the reaction, $1 \mu \mathrm{l}$ of diluted (1/10) SYBR Green I (Molecular Probes, Eugene, OR, USA) was placed on the inner side of the cap of PCR tube. The tube was closed and incubated at $65{ }^{\circ} \mathrm{C}$ for $30 \mathrm{~min}$ in a heating block. On completion of reaction, the tube was centrifuged to allow mixing of SYBR Green I with the amplified product. All positive samples produced a green colour almost immediately upon mixing of SYBR Green I, while the negatives remained orange. The samples were tested in a batch of 24 including clinical samples from patients of Leishmaniasis and other diseases. In every batch, minimum 2 DNA samples from healthy individuals and one blank control in which DNA was replaced by water was used as negative and reagent control, respectively.

\section{Quantitative Real Time PCR (Q-PCR) assay}

SYBR Green I based Leishmania genus specific Q-PCR was performed using F3 and B3 primers using the reaction conditions as described previously [21]. A $10 \mu \mathrm{l}$ of the PCR reaction was performed, consisting of $1 \mathrm{X}$ SYBR Green I PCR Master mix (Applied Biosystems, USA), 5 pmol forward primer F3, 5 pmol reverse primer B3, and $1 \mu \mathrm{l}$ sample DNA. The cycling parameters were $50{ }^{\circ} \mathrm{C}$ for $2 \mathrm{~min}, 95^{\circ} \mathrm{C}$ for $10 \mathrm{~min}$, and 40 cycles of $95{ }^{\circ} \mathrm{C}$ for $15 \mathrm{~s}$ and $60{ }^{\circ} \mathrm{C}$ for $1 \mathrm{~min}$. A standard curve was constructed using 10 -fold serially diluted kDNA plasmid corresponding to $10^{8}$ to $10^{3}$ copies per reaction. A threshold cycle value $(\mathrm{Ct})$ was calculated for each sample by determining the point at which the fluorescence exceeded the threshold limit. All the reactions were performed in triplicate.

\section{Results}

\section{Cloning and sequence analysis of kDNA minicircle}

PCR-amplification of kDNA from total DNA isolated from L. donovani, L. major and L. tropica, using F3 and B3 primers yielded the product of $200 \mathrm{bp}$ size of variable intensity (Fig. 2a). The corresponding amplicons were cloned, sequenced and subjected to multiple sequence alignment. Data revealed 100\% sequence identity in case of L. donovani, $97 \%$ in case of L. major and $96.5 \%$ in case of L. tropica (Fig. 2b).

\section{Determination of kDNA copy number in Leishmania spp. using Q-PCR}

For evaluation of differences in copy number of kDNA minicircle in different Leishmania spp, a standard curve was established with serially diluted known number of kDNA plasmid copies $\left(10^{3}\right.$ to $\left.10^{8}\right)$ from $L$. donovani. The mean standard curve was linear over 6 log range with correlation coefficient $\left(\mathrm{r}^{2}\right)$ of 0.991 (Fig. 2c). A negative control (water instead of template DNA) with each PCR assay was included for stringent measures. Q-PCR assay with parasite DNA from Leishmania spp. revealed that the copy number of kDNA varied from 500-10000 copies in $L$. donovani, 10-20 copies in L. tropica and 1-10 copies in $L$. major.

\section{Analytical sensitivity and specificity of the LAMP assay with Leishmania spp. DNA}

The assay was performed with DNA from $L$. donovani, L. tropica and L. major parasites and found positive in all. Specificity of the assay was evaluated using DNA from microorganisms causative of the common infectious diseases prevalent in India such as Plasmodium spp., Mycobacterium leprae and M. tuberculosis which were all observed to be negative. Further, the analytical sensitivity of the LAMP assay was determined by serial dilution of parasite DNA (10 ng - $1 \mathrm{fg}$ ) from different Leishmania spp. The sensitivity of LAMP assay was higher towards L. donovani (up to $1 \mathrm{fg}$ parasite DNA) and L. tropica (up to $1 \mathrm{pg}$ parasite DNA) as compared to L. major (up 


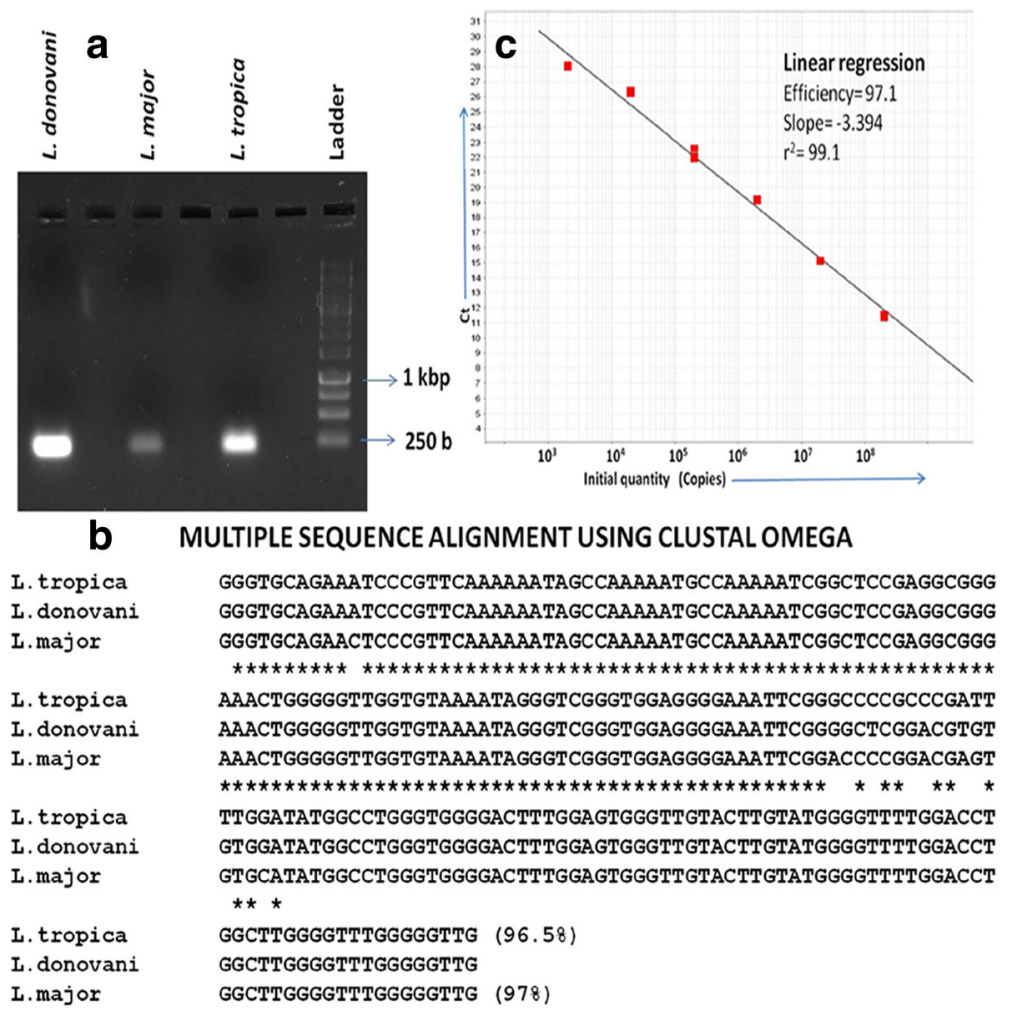

Fig 2 PCR amplification, multiple sequence alignment and standard curve plot. a PCR amplification of kDNA minicircle using parasite DNA from L. donovani, L. major and L.tropica. Product of 200 bp size was obtained in all cases. b Multiple Sequence Alignment using CLUSTAL OMEGA. The amplified kDNA sequences from L. donovani, L. tropica and L. major were sequenced and percentage identity analyzed using Clustal Omega (http://www.ebi.ac.uk/Tools/msa/clustalo/). Percent identity is shown in parenthesis. c Standard curve obtained with serially diluted L. donovani kDNA plasmid. SYBR Green 1 based QPCR was carried out using F3 and B3 primers at each dilution. Graph shows Ct value plotted at different copy number of kDNA

to 100 pg parasite DNA), (Fig. 3a-c). These results correlated well with the intensity of PCR product obtained with $L$. donovani, $L$. tropica and $L$. major (Fig. 2a). The sensitivity of the assay was also determined using DNA isolated from $L$. donovani parasites $\left(10^{5}\right.$ to 10$)$ spiked healthy blood $(200 \mu \mathrm{l})$ and,the LAMP assay could detect the Leishmania DNA up to 10 parasites dilution.

\section{Comparison of detection limits of LAMP and Q-PCR assays}

To assess the threshold detection limit for LAMP and Q-PCR assays for $L$. donovani, the two assays were performed with serial dilutions of kDNA plasmid. The LAMP assay was found positive for $\geq 25$ copies per reaction whereas Q-PCR assay was positive for $\geq 10$ copies per reaction.

\section{Sensitivity and specificity of the LAMP assay in clinical samples}

The clinical applicability of the LAMP assay was assessed using DNA isolated from the clinical samples including blood from cases of VL tuberculosis, malaria and tissue biopsy from cases of PKDL, CL and leprosy. The assay was positive for VL, PKDL and CL samples and negative for all others (Fig. 3d). The LAMP assay was positive in 64 out of 66 confirmed cases of VL using DNA from blood samples, giving a sensitivity of $96.9 \%$ (95\% CI, 89.6-99.2\%). In comparison, the microscopy was positive in 42 of 66 $(63.6 \%)$ cases. The assay was positive in all $(n=15)$ BMA samples of confirmed VL cases at pre-treatment stage giving sensitivity of $100 \%$ (95\% CI, 79.6-100\%). LAMP assay detected parasite DNA in 65 out of 67 confirmed PKDL cases using tissue biopsy, giving sensitivity of $97 \%$ (95\% CI, 89.7-99.2\%) while microscopy was positive in only 21 out of $67(31.3 \%)$ cases. When evaluated in CL cases, the assay was found positive in 8 of 10 cases giving sensitivity of $80 \%$ (95\% CI: $49-94.3 \%)$. The assay was negative in all $(n=100)$ controls (blood, $n=76$; tissue, $n=24)$ giving a specificity of $100 \%$ (95\% CI, $96.3-100 \%)$. These results revealed a high sensitivity (Table 1 ) and specificity (Fig. 3d) of LAMP assay for diagnosis of VL and PKDL.

\section{Assessment of novel LAMP assay as test of cure}

To evaluate the applicability of LAMP assay for assessment of cure in VL and PKDL, 20 cases of VL and 21 


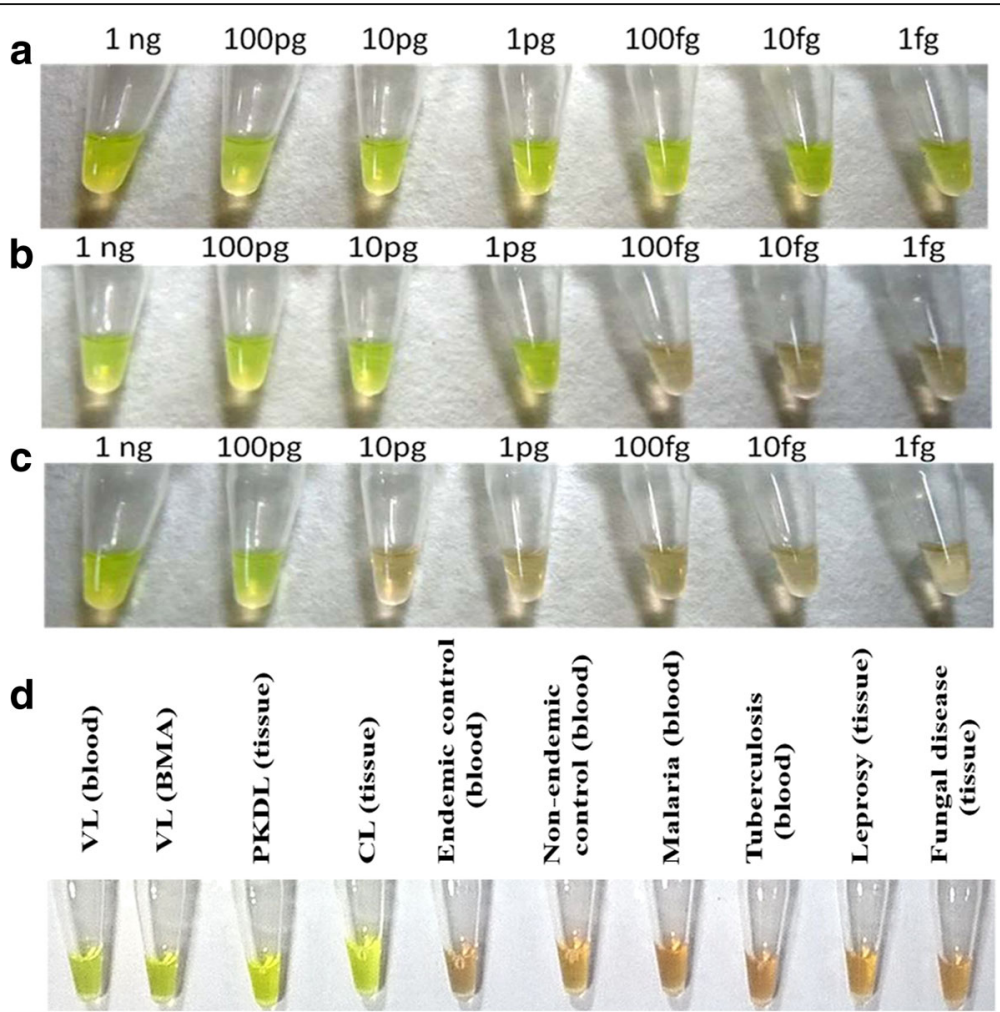

Fig 3 Sensitivity and specificity of LAMP assay. Sensitivity of LAMP assay using serial dilutions of DNA ( $1 \mathrm{ng}-1 \mathrm{fg}$ ) from a L. donovani $\mathbf{b} L$. tropica and $\mathbf{c} L$. major. $\mathbf{d}$ Specificity of LAMP assay for diagnosis of $V L, P K D L$ and $C L$ in clinical samples

cases of PKDL were examined 1-month post-treatment, as reported in our earlier study employing Q-PCR (21, $33)$. When examined at post treatment stage, the VL blood (2 of 20) samples and PKDL tissue (2 of 21) samples from the follow-up samples of the above patients were found to be positive for parasite DNA both by LAMP and QPCR assay. This confirmed that the LAMP and Q-PCR assay correlated well for detection of parasite in clinical samples. Out of the four cases $(2 \mathrm{VL}$ and 2 PKDL) that were positive for parasite at posttreatment stage, two patients (1 VL and 1 PKDL) appeared with relapse.

\section{Discussion}

An effective control of VL and PKDL warrants reliable, rapid and cost effective diagnostic tools. Diagnosis by microscopy is a classical confirmatory test that suffers from low sensitivity. PCR based diagnosis has remained a definitive breakthrough, however, it is a time consuming process and needs sophisticated instruments. A diagnostic test to be prospected as a point-of-care test and to be used in the field settings must qualify two basic criteria: a) high sensitivity and specificity \& b) economical and easy to perform. The widely prevalent rK39 strip test as a diagnostic test is adequate for VL but is of limited value for PKDL diagnosis as a positive result produced may occur due to antibodies persisting due to past episode of VL. Identification of PKDL patients is important to VL Elimination Program [33] as they serve as durable reservoirs during interepidemic episodes, hence, a faster and reliable molecular assay for accurate PKDL diagnosis is warranted. Among molecular diagnostic methods LAMP has emerged as a

Table 1 Sensitivity of the LAMP assay for diagnosis of VL, PKDL and $C L$

\begin{tabular}{llll}
\hline Sample & Cases tested for LAMP (confirmed by Q-PCR ${ }^{\text {ab }}$ ) & Cases positive for LAMP & LAMP Sensitivity (95\% Confidence Interval) \\
\hline VL (Blood) & $66^{\text {a }}$ & 64 & $96.9 \%(89.6-99.2 \%)$ \\
VL (BMA) & $15^{\text {a }}$ & 15 & $100 \%(79.6-100 \%)$ \\
PKDL (Tissue) & $67^{\mathrm{a}}$ & 65 & $97 \%(89.7-99.2 \%)$ \\
CL (Tissue) & $10^{\mathrm{b}}$ & 8 & $80 \%(49-94.3 \%)$ \\
\hline
\end{tabular}

${ }^{\mathrm{a}}$ Reference no. 20

${ }^{\mathrm{b}}$ Reference no. 21 
promising test and has been successfully applied in diagnosis of various protozoan diseases like African trypanosomiasis [34], malaria [35], giardiasis [36], cryptosporidiosis [37] and leishmaniasis [26-32]. The closed tube LAMP assay reported here has the potential as a reliable point of care test for diagnosis of PKDL, with minimal risk of cross-contamination. The LAMP assay using 4 primers that we reported earlier for rapid diagnosis of VL and PKDL [29], was speciesspecific for L.donovani, being negative for L.infantum, L. tropica, and L. major. The novel 6 primer LAMP assay reported here is superior to the previous one, being faster and more sensitive for detection of $L$. donovani. Further, it is applicable for diagnosis of CL since it detects L. tropica and L. major. The assay had the highest sensitivity towards $L$. donovani, being capable to detect $1 \mathrm{fg}$ parasite DNA per reaction that corresponded to less than 1 parasite. The sensitivity and specificity of our LAMP assay is high with a short amplification time. Evaluation of the test in small number of cases of CL gave a sensitivity of $80 \%$; however, a study is warranted in large number of cases to explore its utility for diagnosis of CL.

We sought to address whether the lower sensitivity of detection in $L$. major and L. tropica was due to difference in sequence or copy number of the target kDNA. It is well known that all copies of kDNA within a parasite kinetoplast are not identical and variations in the target minicircle sequences are observed. Here, a base difference in the sequence of the chosen minicircle amplicon at the forward primer site in case of $L$. major DNA was observed. This may explain the reduced sensitivity of the assay to detect $L$. major spp. Q-PCR assay showed variations in minicircle copies from 500-10000 in L. donovani strains, 10-20 copies in L. tropica and 1-10 copies in $L$. major, although, estimates of the copy number for $L$. major is not conclusive due to variation in L. major targeted sequence at forward Q-PCR primer site.

In the present study we have chosen Q-PCR (21) as the reference test as it is reported as one of the most sensitive molecular assay to detect parasite DNA in clinical samples, therefore, we compared the threshold detection limit of kDNA copies by LAMP vs. Q-PCR assay. The threshold copy number detection limits for LAMP and Q-PCR assays were determined as $\geq 25$ copies and $\geq 10$ copies, respectively. The comparative detection limits for the two assays were similar to that reported for detection of orf virus [38]. Thus, with the sensitivity comparable to Q-PCR (both detects up to 1 fg DNA), LAMP assay can undoubtedly be volunteered as an efficient tool for diagnosis of VL and PKDL as it is simpler, faster and easy to perform. In addition, LAMP assay efficiently detected parasite DNA in the same VL $(n=2 / 20)$ and PKDL $(n=2 / 21)$ cases at post-treatment stage which were detected positive for parasite DNA by Q-PCR as reported earlier [21,39]. Close agreement in the results of LAMP and Q-PCR assays at post-treatment stage highlights the utility of LAMP assay as a point-of-care test for assessment of cure of VL and PKDL cases, though a detailed evaluation of the assay in a large number the patients is required to appraise its prognostic efficacy. The less invasive methods of sample collection like finger prick blood sampling and direct LAMP assays avoiding the DNA isolation steps are desirable for field based diagnosis.

Despite the numerous advantages, LAMP assay faces a major issue of product cross-contamination that limits its application in the field. In the past, LAMP assays using wax dye capsule method, calcein or hydroxyl-napthol blue metal indicators at the start of the reaction were introduced to prevent opening of lid after amplification [40]. Our closed tube LAMP assay using SYBR green I is a further improvement as this indicator gives better sensitivity and clarity in visualization of the results.

\section{Conclusions}

The LAMP assay developed in the present study can detect DNA from L. donovani, L. tropica and L. major parasites; hence it is applicable for the rapid and reliable diagnosis of VL, PKDL and CL. The method is easy to perform, cost-effective and rapid with much reduced reaction time of 30 mins. Above all, the need to open the tube for adding SYBR Green I for detection of amplification is not required, ruling out the occurrence of false positive results. All the above factors justify the use of the presently defined LAMP assay in large epidemiologic studies to be performed in field settings. To conclude, the LAMP assay developed by us falls in the category of high performance result oriented tests having rapid turnaround time with a minimal chance of error. Thus, we propose that the reformed LAMP assay reported here may be exploited as a point of care test for diagnosis as well as for assessment of cure for both VL and PKDL.

\section{Acknowledgements \\ We express our sincere gratitude to the patients for giving consent to be a part of the study and whomsoever dedicated time to come for their follow up visits.}

Funding

This work was supported by Indian Council of Medical Research (ICMR), India.

Availability of data and materials

All data supporting our findings are present in this manuscript.

\section{Authors' contributions}

Conceived and designed the experiments: SV, RS, PS. Performed the experiments: SV, VS. Analyzed the data: SV, VS, RS and PS. Sample collection: NSN, VR and RAB. Wrote the paper: SV, VS, RS and PS. All authors read and approved the final manuscript.

Competing interests

The authors declare that they have no competing interests.

Consent for publication

Not applicable. 


\section{Ethics approval and consent to participate}

The study was approved by and carried out under the guidelines of the Ethics Committee, VMMC \& Safdarjung Hospital, New Delhi, India. All patients or responsible adults provided written informed consent for the collection of samples and subsequent analysis.

\section{Publisher's Note}

Springer Nature remains neutral with regard to jurisdictional claims in published maps and institutional affiliations.

\section{Author details}

${ }^{1}$ National Institute of Pathology (ICMR), Safdarjung Hospital Campus, New Delhi 110029, India. ${ }^{2}$ Department of Skin, STD and Leprosy, S. P. Medical College, Bikaner, India. ${ }^{3}$ Department of Medicine, Safdarjung Hospital, New Delhi, India. ${ }^{4}$ Department of Dermatology, Safdarjung Hospital, New Delhi, India.

Received: 6 August 2016 Accepted: 10 March 2017

Published online: 23 March 2017

\section{References}

1. World Health Organization. Leishmaniasis in high-burden countries: an epidemiological update based on data reported in 2014. World Health Organ, Week Epidemiol Rec. 2016.

2. Rahman K, Islam S, Rahman M, Kenah E, Galive C, Zahid M, et al. Increasing incidence of post-kala-azar dermal leishmaniasis in a population-based study in Bangladesh. Clin Infect Dis. 2010;50(1):73-6.

3. Ramesh V, Kaushal H, Mishra A, Singh R, Salotra P. Clinico-epidemiological analysis of post kala-azar dermal leishmaniasis (PKDL) cases in India over last two decades: a hospital based retrospective study. BMC Public Health. 2015;15:1092

4. Desjeux P, Ghosh R, Dhalaria P, Strub-Wourgaft N, Zijlstra E. Report of the Post Kala-Azar Dermal Leishmaniasis (PKDL) consortium meeting, New Delhi, India, 27-29 June 2012. Parasit \& Vectors. 2013;6:196.

5. Kumar R, Bumb RA, Ansari NA, Mehta RD, Salotra P. Cutaneous leishmaniasis caused by Leishmania tropica in Bikaner, India: parasite identification and characterization using molecular and immunologic tools. Am J Trop Med Hyg. 2007;76(5):896-901.

6. Siddig M, Ghalib H, Shillington D, Petersen E. Visceral leishmaniasis in the Sudan: comparative parasitological methods of diagnosis. Trans R Soc Trop Med Hyg. 1988;82(1):66-8.

7. Salotra P, Singh R. Challenges in the diagnosis of post kala-azar dermal leishmaniasis. Indian J Med Res. 2006;123(3):295-310

8. Salotra P, Sreenivas G, Ramesh V, Sundar S. A simple and sensitive test for field diagnosis of post kala-azar dermal leishmaniasis. Br J Dermatol. 2001;145(4):630-2.

9. Salotra P, Sreenivas G, Nasim A, Subba Raju B, Ramesh V. Evaluation of enzyme-linked immunosorbent assay for diagnosis of post-kala-azar dermal leishmaniasis with crude or recombinant k39 antigen. Clin Diagn Lab Immunol. 2002;9(2):370-3.

10. Singh R, Raju BVS, Jain RK, Salotra P. Potential of direct agglutination test based on promastigote and amastigote antigens for serodiagnosis of postkala-azar dermal leishmaniasis. Clin Diagn Lab Immunol. 2005;12(10):1191-4.

11. Srividya G, Kulshrestha A, Singh R, Salotra P. Diagnosis of visceral leishmaniasis: developments over the last decade. Parasitol Res. 2011;110(3):1065-78.

12. Salotra P, Sreenivas G, Pogue G, Lee N, Nakhasi H, Ramesh V, et al. Development of a species-specific PCR assay for detection of Leishmania donovani in clinical samples from patients with kala-azar and post-kala-azar dermal leishmaniasis. J Clin Microbiol. 2001;39(3):849-54.

13. Schönian G, Nasereddin A, Dinse N, Schweynoch C, Schallig H, Presber W, et al. PCR diagnosis and characterization of Leishmania in local and imported clinical samples. Diagn Microbiol Infect Dis. 2003;47(1):349-58.

14. Antinori S, Calattini S, Longhi E, Bestetti G, Piolini R, Magni C, et al. Clinical use of polymerase chain reaction performed on peripheral blood and bone marrow samples for the diagnosis and monitoring of visceral leishmaniasis in hiv-infected and hiv-uninfected patients: a single-center, 8-year experience in Italy and review of the literature. Clin Infect Dis. 2007;44(12):1602-10.

15. Reithinger R, Dujardin J. Molecular diagnosis of leishmaniasis: current status and future applications. J Clin Microbiol. 2006;45(1):21-5.

16. Gonçalves-de-Albuquerque S, Pessoa e Silva R, De Morais R, Trajano-Silva L, Régis-da-Silva C, Brandão-Filho S, et al. Tracking false-negative results in molecular diagnosis: proposal of a triplex-PCR based method for leishmaniasis diagnosis. J Venom Anim Toxins Incl Trop Dis. 2014;20:16. doi:10.1186/1678-9199-20-16.

17. Rodriguez-Gonzalez I, MarÃn C, Longoni S, Mateo H, Alunda J, Minaya G, et al. Identification of New World Leishmania species from Peru by biochemical techniques and multiplex PCR assay. FEMS Microbiol Lett. 2007;267(1):9-16. http://dx.doi.org/10.1111/j.1574-6968.2006.00574.x.

18. Sreenivas G, Ansari N, Kataria J, Salotra P. Nested PCR assay for detection of Leishmania donovani in slit aspirates from post-kala-azar dermal leishmaniasis lesions. J Clin Microbiol. 2004;42(4):1777-8.

19. Mary C, Faraut F, Lascombe L, Dumon H. Quantification of Leishmania infantum DNA by a real-time PCR assay with high sensitivity. J Clin Microbiol. 2004;42(11):5249-55.

20. Verma S, Kumar R, Katara GK, Singh LC, Negi NS, Ramesh V, et al. Quantification of parasite load in clinical samples of leishmaniasis patients: IL-10 level correlates with parasite load in visceral leishmaniasis. PLoS One 2010;5:e10107. doi:10.1371/journal.pone.0010107.

21. Kumar R, Bumb R, Salotra P. Correlation of parasitic load with interleukin-4 response in patients with cutaneous leishmaniasis due to Leishmania tropica. FEMS Immunol Med Microbiol. 2009;57(3):239-46.

22. Sudarshan $M$, Singh $T$, Singh $A$, Chourasia A, Singh B, Wilson $M$, et al. Quantitative PCR in epidemiology for early detection of visceral leishmaniasis cases in India. PLoS Negl Trop Dis. 2014;8(12):e3366.

23. Notomi T, Okayama H, Masubuchi H, Yonekawa T, Watanabe $\mathrm{K}$, Amino N, et al. Loop-mediated isothermal amplification of DNA. Nucleic Acids Res. 2000;28:E63. http://dx.doi.org/10.1093/nar/28.12.e63.

24. Mori Y, Notomi T. Loop-mediated isothermal amplification (LAMP): a rapid, accurate, and cost-effective diagnostic method for infectious diseases. J Infect Chemother. 2009;15(2):62-9.

25. Kaneko H, Kawana T, Fukushima E, Suzutani T. Tolerance of loop-mediated isothermal amplification to a culture medium and biological substances. J Biochem Biophys Methods. 2007;70(3):499-501.

26. Takagi H, Itoh M, Islam M, Razzaque A, Ekram A, Hashighuchi Y, et al. Sensitive, specific, and rapid detection of Leishmania donovani DNA by loop-mediated isothermal amplification. Am J Trop Med Hyg. 2009;81(4):578-82.

27. Adams E, Schoone G, Ageed A, Safi S, Schallig H. Development of a reverse transcriptase loop-mediated isothermal amplification (LAMP) assay for the sensitive detection of Leishmania parasites in clinical samples. Am J Trop Med Hyg. 2010;82(4):591-6.

28. Khan M, Bhaskar K, Salam M, Akther T, Pluschke G, Mondal D. Diagnostic accuracy of loop-mediated isothermal amplification (LAMP) for detection of Leishmania DNA in buffy coat from visceral leishmaniasis patients. Parasit Vectors. 2012:5:280.

29. Verma S, Avishek K, Sharma V, Negi NS, Ramesh V, Salotra P. Application of loop-mediated isothermal amplification assay for the sensitive and rapid diagnosis of visceral leishmaniasis and post-kala-azar dermal leishmaniasis. Diagn Microbiol Infect Dis. 2013;75(4):390-5.

30. Ghasemian M, Gharavi MJ, Akhlaghi L, Mohebali M, Meamar AR, Aryan E, et al. Development and assessment of loop-mediated isothermal amplification (LAMP) assay for the diagnosis of human visceral leishmaniasis in Iran. Iran J Parasitol. 2014;9(1):50-9.

31. Sriworarat $C$, Phumee A, Mungthin M, Leelayoova S, Siriyasatien P. Development of loop-mediated isothermal amplification (LAMP) for simple detection of Leishmania infection. Parasit Vectors. 2015;8:591.

32. Abbasi I, Kirstein OD, Hailu A, Warburg A. Optimization of loop-mediated isothermal amplification (LAMP) assays for the detection of Leishmania DNA in human blood samples. Acta Trop. 2016;162:20-6.

33. World Health Organization. Control of the leishmaniases. World Health Organ, Tech Rep Ser. 2010;949:22-6.

34. Njiru Z, Mikosza A, Armstrong T, Enyaru J, Ndung'u J, Thompson A. Loopmediated isothermal amplification (LAMP) method for rapid detection of Trypanosoma bruceirhodesiense. PLoS Negl Trop Dis. 2008;2(1):e147.

35. Singh R, Savargaonkar D, Bhatt R, Valecha N. Rapid detection of Plasmodium vivax in saliva and blood using loop mediated isothermal amplification (LAMP) assay. J Infect. 2013;67(3):245-7.

36. Plutzer J, Karanis P. Rapid identification of Giardia duodenalis by loopmediated isothermal amplification (LAMP) from faecal and environmental samples and comparative findings by PCR and real-time PCR methods. Parasitol Res. 2009;104(6):1527-33.

37. Bakheit M, Torra D, Palomino L, Thekisoe O, Mbati P, Ongerth J, et al. Sensitive and specific detection of Cryptosporidium species in PCRnegative samples by loop-mediated isothermal DNA amplification and 
confirmation of generated LAMP products by sequencing. Vet Parasitol. 2008;158(1-2):11-22.

38. Wang G, Shang Y, Wang Y, Tian H, Liu X. Comparison of a loop-mediated isothermal amplification for orf virus with quantitative real-time PCR. Virol J. 2013;10:138.

39. Verma S, Bhandari V, Avishek K, Ramesh V, Salotra P. Reliable diagnosis of post-kala-azar dermal leishmaniasis (PKDL) using slit aspirate specimen to avoid invasive sampling procedures. Trop Med Int Health. 2012;18(3):268-75.

40. Karthik K, Rathore R, Thomas P, Arun T, Viswas K, Dhama K, et al. New closed tube loop mediated isothermal amplification assay for prevention of product cross-contamination. MethodsX. 2014;1:137-43.

Submit your next manuscript to BioMed Central and we will help you at every step:

- We accept pre-submission inquiries

- Our selector tool helps you to find the most relevant journal

- We provide round the clock customer support

- Convenient online submission

- Thorough peer review

- Inclusion in PubMed and all major indexing services

- Maximum visibility for your research

Submit your manuscript at www.biomedcentral.com/submit 